\title{
Determining hydrocarbon generation and migration using noble gases
}

DAVID J. BYRNE', P.H. BARRY' ${ }^{2}$, M. LAWSON ${ }^{3}$, R.L. TYNE$^{4}$, C.J. BALLENTINE ${ }^{4}$

Centre de Recherches Pétrographiques et Géochimiques, Nancy, France

${ }^{2}$ Woods Hole Oceanographic Institution, MA, USA

ExxonMobil Exploration Company, Spring, TX, USA

'Dept of Earth Sciences, University of Oxford, UK

Noble gases are inert geochemical tracers, and have previously been used to understand hydrocarbon generation, migration and residences times Earth's crust [1]. The recent proliferation of unconventional hydrocarbon production from source-rock reservoirs has enabled geochemical analysis of hydrocarbons directly from their generation environments [2]. This greatly enhances our capability to understand the geochemical evolution of the petroleum system as a whole.

We use multiple case studies [3-4] to demonstrate how hydrocarbon generation and migration affect noble gas isotopes and relative abundances. We then show how the interpretation of these signatures can be used to elucidate the physical processes occurring at each stage of the evolution of the wider petroleum system.

In the Eagle Ford unconventional source-rock reservoir, we analysed natural gas samples generated and produced in-situ over a range of different burial depths, and thus, thermal maturities [3]. We showed that groundwater-derived noble gases, such as $36 \mathrm{Ar}$, are diluted by continued gas generation as the thermogenic cracking of kerogen proceeds. This process can be utilised to quantitatively determine the volumes of gas generated within the source-rock, as well as to estimate the amount of gas retained within or expelled from the system.

In the East Texas basin we analysed natural gas samples produced from both source-rock reservoirs and several overlying conventional reservoirs [4]. We showed that increased migration distance led to greater entrainment of atmospheric noble gas isotopes $\left({ }^{20} \mathrm{Ne}\right.$, ${ }^{36} \mathrm{Ar}$ ) derived from groundwater, as well as greater amounts of radiogenic isotopes $\left({ }^{4} \mathrm{He},{ }^{40} \mathrm{Ar}\right)$, and mantlederived ${ }^{3} \mathrm{He}$. This observation can be used as a proxy for migration distance (e.g., to quantify the relative volume of rock encountered by a migrating gas phase) and as an indicator of the style of migration pathways (i.e., diffuse vs. focused).

[1] Byrne et al., 2017, GeolSoc Spec Pubs. [2] Curtis, AAPG Bull. [3] Byrne et al., 2018 GCA. [4] Byrne et al., 2020 GCA. 
This abstract is too long to be accepted for publication.

Please revise it so that it fits into the column on one page. 